\title{
Lo nacional en crisis: formación en dramaturgia a finales de los años '6o
}

\author{
( Mariano Saba \\ Instituto de Filología y Literaturas Hispánicas “Dr. Amado Alonso”, UBA / \\ CONICET, Argentina \\ marianosaba@gmail.com
}

Fecha de recepción: 24/02/2021. Fecha de aceptación: 20/03/2021.

\begin{abstract}
A fines de los '60 la percepción contextual de una crisis en la existencia del autor nacional parece haber sido condición de posibilidad para la aparición de seminarios y talleres de dramaturgia, los cuales justamente terminarían dando formación iniciática a los escritores del género cuya presencia sería central en los años posteriores. En este sentido, conviene analizar no sólo la paradoja por la cual la polémica dio estímulo a la enseñanza, sino también los hitos más relevantes que surgieron entonces como nodos de formación en la escritura teatral.
\end{abstract}

PALABRAS CLAVE: DÉCADA DE LOS '6o, DRAMATURGIA NACIONAL, FORMACIÓN, ENSEÑANZA, IMAGEN.

\section{The National Being in Crisis: Training in Dramaturgy at the End of the 60 s}

At the end of the 1960s, the perception of a crisis in the existence of the national author seems to have been a condition of possibility for the appearance of dramaturgy seminars and workshops, which would give initiation training to the central writers in later years. In this sense, it is convenient to analyze not only the paradox by which the controversy stimulated teaching, but also the most relevant artists that emerged then as referents of training in theater writing.

KEYWORDS: 1960S, NATIONAL DRAMATURGY, TRAINING, TEACHING, IMAGE.

Hacia fines de la década del 60 resulta identificable la confluencia de dos factores determinantes para el contexto específico de la dramaturgia local. Por un lado, es inocultable la emergencia de un tema que reaparece en la prensa cultural del período y que se percibe, una y otra vez, como problema a debatir y a resolver: la escasez de autores nacionales cuyo aglutinamiento permitiera definir cierta identidad común dentro de la praxis dramatúrgica local. Por otra parte, y específicamente hacia el 
año 1970, se produce cierta paradójica multiplicación de núcleos de formación en dramaturgia -ligados al formato taller-cuya existencia fue prolegómeno evidente de la proliferación que la enseñanza de esa disciplina tendría durante las décadas siguientes. En este sentido, cabe destacar la ausencia de planteos previos que hayan puesto en vínculo ambas circunstancias.

Así, es factible arriesgar la hipótesis de que, en el contexto preciso de ese cambio de década, comienza a producirse una transición paulatina entre cierto perfil de aprendizaje autónomo y una asistencia más asidua a clases grupales. Es decir, se habría empezado, entonces, a producir un pasaje desde la experiencia formativa por expectación de modelos teatrales -los cuales podían brindarse al autor por su pertenencia al periodismo cultural o por su inmersión en la práctica del teatro independiente-, hacia la sistematización de la enseñanza técnica de la escritura teatral a través de talleres específicamente abocados a ella. Previamente a la aparición de los varios talleres que se darían a fines de los años ' 60 , la formación en dramaturgia parecía seguir un patrón doble: en primer lugar, los dramaturgos ligados al modelo de la praxis de grupos independientes, quienes desde roles diversos (la actuación, la asistencia o la dirección) comienzan a transitar formas primerizas de la práctica dramatúrgica ${ }^{1}$; y en segunda instancia, los dramaturgos provenientes del ámbito periodístico, los cuales muchas veces decantan sus variantes personales del contacto con modelos cuya expectación demandaba la práctica de la crítica cultural. Ya provinieran de una u otra opción, los autores dramáticos de mediados de los años '60 parecen capitalizar cierta técnica dramatúrgica a partir de su cercanía con núcleos arraigados en la participación o expectación de prácticas escénicas concretas, cuya dimensión modélica constituía criterio para intentar las propias pruebas.

Ahora bien, es indudable que el debate sobre la crisis en la autoría nacional acompaña paradójicamente durante todo ese período la emergencia de talleres y alternativas inéditas hasta entonces para la formación de dramaturgos. El primero de los dos testimonios que conviene evocar es un reportaje que Pirí Lugones realiza a tres jóvenes dramaturgos que define como la nueva generación: Roberto Cossa, Germán Rozenmacher y Rodolfo Walsh. Publicada en Tiempos modernos, en julio de 1965, la entrevista toma la forma propia de una obra teatral dividida en cuatro escenas. En cada sección, Lugones oficia de moderadora y estimula un diálogo que deja ver los temas más relevantes para esos tres exponentes. Cada uno de estos escritores cuenta ya por entonces con un estreno relevante: respectivamente, Nuestro fin de semana, Réquiem para un viernes a la noche y La granada. Los tres autores comparten sus experiencias de inicio y coinciden con el intento de cursar previamente alguna carrera universitaria (excepto Rozenmacher, que aclara estar concluyendo Letras gracias a la ayuda de su pareja). Ante la pregunta de por qué han optado en algún momento por el género teatral, Cossa y Walsh concuerdan en que la experiencia común podría ser cierto placer por el diálogo. De hecho, Cossa afirma: "Vos llegás al teatro porque el diálogo te carbura, te resulta fácil, es una expresión directa en uno. Además yo vengo de una familia de actores..." (en Rozenmacher, 2013: 880). Lo más interesante del reportaje es la evidencia de cierta preocupación común sobre la vitalidad de una sostenida dramaturgia nacional. Lugones pregunta si consideran justo pensarse a sí mismos (junto con De Cecco) como parte de una "renovación del teatro argentino" (884). Cossa sostiene que tres autores no alcanzan para tal dimensión y Rozenmacher, luego de evocar también el nombre de Halac, opina:

1. Esta situación parece desprenderse de modelos incluso previos. Tal como ha mencionado Mauricio Kartun en una entrevista al respecto: "El aprendizaje se producía por trabajar con "parejero", con el tipo con el que laburás al lado, con otro que está escribiendo y empezás a escribir con él. Es muy común en las primeras décadas del siglo XX cuando ves las publicaciones de Bambalinas, ver autores muy conocidos que laburaban con otros autores, como Discépolo - De Rosa. Había mucho de juntarse, y esta era una manera de aprender. Siempre que compartís la angustia con otro, aprendés” (Kartun: 2019). 
...esta es una de las características de nuestra sociedad subdesarrollada clase A: la necesidad desesperada que sentimos por tener un cine o una dramaturgia. Debemos tener mucho cuidado en no inventar. Lo menos que podemos tener es mucha lucidez y mucha modestia para calificar, para tipificar. (884)

Rozenmacher identifica el problema y algo de eso se asocia al perfil que Walsh considera deseable para el dramaturgo:

Teniendo en cuenta el tipo de país que somos, semidependiente, en donde el escritor tiene, además de la función de creación artística o de placer estético, que no puede renunciar, otra función, que es la del hombre de lucha. A esta altura de las cosas ya no se puede ser un mero esteta. (885)

Esta opinión de Walsh resulta compartida por Rozenmacher, advirtiendo este sin embargo el peligro del propagandismo:

Ese es un peligro, el otro es que uno empieza solo. Arlt, Payró, Sánchez, empiezan solos. En cuanto a lograr la creación del mundo artístico de uno y hablar de cosas que a uno le permitan actuar como escritor militante, sin hacer panfleto, es un laburo de la gran... (885)

El modelo es, para los tres autores, Arthur Miller. Y tal como puede desprenderse entonces de estos elementos, el panorama de mediados del 60 aglutina, por un lado, el reconocimiento de una ansiedad cultural por identificar los rasgos de una dramaturgia propia, nacional - una dramaturgia cuyo modelo debía ser el del artista comprometido con su contexto, aun cuando el referente indeclinable no fuera local sino norteamericano-; y, por otra parte, la conciencia de una formación poco sistemática y solitaria, la cual al menos desde la óptica de Rozenmacher parecía comportar el peligro del aislamiento. La única clave que parece reunirlos en torno a un proyecto común es la pertinencia de un realismo de amplitud total que permitiera reflejar, desde distintos lenguajes, lo que Cossa llama "una realidad nuestra permanente y vigente" (887). O tal como confiesa Walsh: "Sí, yo trato de evadirme a veces pero no puedo. La realidad argentina y latinoamericana pesan en mí de una forma abrumadora" (887).

Diez años después, un segundo ejemplo nos permite constatar la persistencia de la polémica sobre la crisis del autor nacional. En mayo de 1975, Luis Ordaz intenta describir para la Sociedad Hebraica un panorama del último medio siglo del teatro argentino. Vale destacar su énfasis en el teatro independiente como usina de la dramaturgia local. Menciona que hacia 1940 el movimiento de los escenarios libres es el acontecimiento teatral más relevante de la época, lo cual contrastaría con su presente:

En estos momentos vivimos en una especie de callejón teatral, del que no se sabe cómo salir, y caben algunas reflexiones. Un teatro nacional debe hacerse (no puede ser de otra manera), con autores nacionales. (...) Y si en la actualidad es muy difícil, y sólo de manera oficial muy precaria, por lo común, retomar algunas obras de nuestro repertorio dramático, resulta casi imposible a los nuevos creadores llegar a un tablado. (2005: 211)

Ordaz culpa del sofocamiento a los obstáculos políticos de los años previos, pero más allá de eso enfatiza nuevamente la necesidad de preservar al ámbito independiente como cauce de incorporación de nuevas voces.

Como es de notar, entonces, entre 1965 y 1975 la recurrencia del problema en torno a la crisis del autor nacional va enhebrándose junto a los paradójicos hitos dramatúrgicos del período que no dejan de emerger. Al respecto, y justo en el año de 1970, 
Rozenmacher publica en la revista Siete Días Ilustrados un extenso panorama que plasma de manera notable la dimensión del tema para ese momento. "Teatro argentino. Nacionalizar a toda costa" se llama el artículo donde el autor define un contexto que, a pesar de considerarse como cuarto centro teatral del mundo, está "agobiado por el subdesarrollo cultural" (Rozanmacher, 2013: 815). Los argumentos de tal diagnóstico son variados: el artículo parte de una opinión vertida por Jean Vilar en su visita al país, según la cual el teatro argentino se asemejaría al francés en su costumbre de convertir la realidad asfixiante en un lugar común. Rozenmacher rescata la idea de Vilar: “...el panorama argentino es igual al francés. Ambos estamos colonizados y por eso aquí, como en Francia, la consigna es nacionalizar a toda costa" (816). El artículo postula la necesidad de preguntarse cómo si Argentina sigue siendo dolorosamente un país de segunda clase, puede pretender contar con un teatro de primera. Entre opiniones de muchos notables del campo, el texto va preguntándose, así, por los modos posibles de una nacionalización cuyo efecto fuera la emancipación y consolidación de un teatro propio. Recoge, por ejemplo, la opinión de Carlos Gandolfo, quien expresa:

Todo el mundo se tira al éxito, a situaciones conquistadas y status, nadie arriesga por miedo a quemarse. (...) Así, faltan autores que salgan de la mera descripción de la clase media conformista; falta imaginación y coraje, y situaciones fuertes, acción rica e imaginativa (en Rozenmacher, 2013: 818).

Aquel realismo que en 1965 parecía tronco común de los diversos lenguajes dramatúrgicos locales, empieza a ser impugnado hacia 1970 como formato simplificado y recursivo, lo cual condenaría a la escena a cierto declive. Rozenmacher reflexiona al respecto: "Hay algunas explicaciones para esta monocorde medianía: la falta de una antigua tradición teatral es una razón atendible. Pero la carencia de una sólida corriente de autores nacionales resulta sin duda una causa de mayor peso" (819). Por su parte, entre los consultados, el director Mario Rolla sugiere que los directores "quieren hacer autores nacionales (...) ¡Pero en el medio hay algo, una resistencia, una desconfianza básica!" (820). Gandolfo, por su parte, enfatiza la distancia entre los rubros de la dirección y la escritura: "hay un gran malentendido entre ambos y tal vez sería oportuno realizar un largo, intenso seminario conjunto" (820). Las opiniones que se van volcando durante ese momento en torno a la crisis de la dramaturgia nacional, no sólo exponen la carencia de autores como problema básico, junto con la repetida ansiedad por conquistar experiencias teatrales y escrituras equiparables con los cánones europeos, sino que exigen cada tanto la necesidad de estimular la existencia de nuevos dramaturgos a través de propuestas formativas. Carlos Somigliana, por ejemplo, declara:

...este es un medio inveteradamente ansioso que no se busca con autenticidad y por eso siempre ansía tener sus Albees o Pinters y cambia de modelo de teatro conforme a las corrientes de las metrópolis. (...) Eso explica que escritores como Osvaldo Dragún o Agustín Cuzzani estén terminados a los cuarenta años y que nosotros mismos, que todavía no llegamos a esa edad, estemos desorientados y perplejos, sin saber si escribir o no, y aun en caso afirmativo, sobre qué escribir y en qué forma. (En Rozenmacher, 2013: 824)

Rozenmacher termina la sólida descripción de su época con una propuesta clara de nacionalización -la cual no dista de sus intuiciones de los años previos expresadas a Pirí Lugones-: "Para algunos llegó la hora de romper tabúes y acometer un teatro político: no es casual que existan varios proyectos donde, en el fondo, el personaje central del espectáculo sea el peronismo" (830). Sugiere que la clave vaya a buscarse en la obligación de alertar contra las falsas opciones que campean el teatro y remite a Discépolo, como símbolo de que la dramaturgia nacional no debe hallarse en los "supermarkets del espectáculo" (830) sino "en la búsqueda de productos monstruosos, 
sin antecedentes, como los inéditos personajes de Mateo o Stéfano" (830). "Sólo a partir del hombre de aquí se alcanzará la universalidad", concluye el cronista.

Osvaldo Pellettieri (1997) ha leído el panorama de Rozenmacher como la revelación de una "estructura de sentimiento" (212) del momento, según la cual los setenta resultaban "un amargo despertar luego del 'boom' de la década anterior" (212), un paisaje signado por la crisis, la caída de público, la declinación del teatro independiente. Es por esto que el pedido de concretar un teatro de intertexto político podía insertarse claramente "en el llamado 'pensamiento nacional' que oponía conflictivamente la "cultura de lo nuestro a la 'cultura de lo ajeno"' (Pellettieri, 1997: 212).

Ahora bien, conviene destacar que, a pesar de la sensación de crisis de la figura de autor nacional, hacía tiempo que existía un crecimiento identificable de dramaturgos arraigados en la cosmovisión local. La crisis del autor nacional parece, en realidad, configurarse como una constante de reaparición frecuente cuya persistencia permite identificar el revés paradójico de la supuesta carencia: es decir, la existencia prolífica hacia el año 1970 de una dramaturgia local que no solo produce cierta textualidad particular, sino que empieza también a ocuparse de la objetivación técnica de su hechura y de la transmisión didáctica de sus saberes a través de experiencias grupales de talleres y seminarios. En este sentido, resulta llamativo lo poco que se ha enfatizado la relación potencial que tuvo que haber existido entre la percepción crítica del teatro nacional en 1970 y cierto inicio proliferante de núcleos de interés para la formación local en dramaturgia.

Difícil de ver para los artistas inmersos en el campo teatral de entre décadas, puede afirmarse, sin embargo, que la identificación de esa necesidad de una dramaturgia nacional pronto encuadraría en un panorama más abarcador -y hasta latinoamericanista- de reivindicación autóctona del pensamiento y de la cultura propios. Dos contextualizaciones críticas colaboran con la comprensión, en primer lugar, del contexto emancipador hacia fines de los años 60 y, en segunda instancia, de la fuerza de arrastre que esa conciencia crítica significó para el surgimiento y proliferación de núcleos de formación dramatúrgica hacia la década siguiente.

La primera descripción de contexto que debe tenerse en cuenta es la que desarrolla Pellettieri (1997) en torno a lo que dio en llamar "período de intercambio de procedimientos" (entre absurdistas y realistas) de 1967 a 1976. En su opinión, el período "fue de clara politización y nacionalización de la cultura dentro del campo" (202). Los rasgos más importantes fueron la revalorización del peronismo desde la izquierda así como las intromisiones en el campo intelectual por parte de las dictaduras y del último tiempo del gobierno peronista. Sin embargo, lo que más interesa es que el período motiva un repliegue del pensamiento sobre el tema de lo nacional: "Los cambios de circulación de la cultura preexistente se concretaron alrededor del redescubrimiento de lo nacional en el plano cultural y también en el político" (Pellettieri, 1997: 209). La sociología del momento se vuelca a la reelaboración de cierta problemática ligada a la dependencia y a la identidad cultural. Y esta tendencia, claramente, no permanece ajena al teatro. Hacia 1969, con el cierre de Nuevo Teatro, el panorama descripto por Pellettieri confirma la decadencia económica y el declive del teatro independiente de Buenos Aires. Las presiones del campo de poder sobre los intelectuales configuran la emergencia de un "teatro de parodia al intertexto político" (210) donde la nueva dramaturgia -menos prolífica que en los años previos- destaca, por ejemplo, en Ricardo Monti.

No parece un detalle menor que Monti surja específicamente en este momento ${ }^{2}$, sobre todo al considerar que con el correr del tiempo sería figura pionera en la constitución

2. Conviene recordar que es casualmente en el año de 1970 que Hubert Copello estrena Una noche con el Sr. Magnus \& hijos. 
de talleres de dramaturgia en Buenos Aires y que modificaría la metodología de formación haciendo énfasis en la imagen -y ya no en la idea o en el tema- como pilar del proceso creador. Y más significativa resulta esta asociación cuando se evoca el segundo panorama en torno al período y que es el detallado por Marina Pianca (1990) en su estudio El teatro de nuestra América: un proyecto continental (1959-1989). Pianca sostiene que la segunda mitad del siglo XX está signada por "dos visiones contradictorias para la concreción de un destino latinoamericano" (15). Se refiere, por un lado, al ideario sarmientino, apegado a la idea de progreso implementada tanto por Estados Unidos como por modelos europeos; y, por otra parte, el proyecto de José Martí, receloso del colonialismo y abocado a consolidar la noción de una América libre. A partir de esta base, Pianca intenta hallar una periodización aglutinante dentro de la heterogeneidad del teatro latinoamericano. Entre 1959 y 1968 reconoce un primer lapso en que la dramaturgia nacional es frecuentemente postergada "frente a una producción canónica "universal”" (16). En cambio, entre 1968 y 1974 "se intenta lograr esa homología estructural en una búsqueda consciente de esa homologación que lleva a la reestructuración y redefinición de todo el paradigma teatral" (17). Este segundo período vendría a intentar "la formulación de un teatro latinoamericano consecuente con el devenir histórico del continente" (17).

Así, tal como puede extraerse de los estudios de fondo que intentan describir la transición entre los últimos años de la década del 60 y el inicio de los años '70, tanto a nivel local como a nivel continental la sensación es la de una crisis de renovación cuyos intereses parecen volcarse al reconocimiento de una identidad propia, y también de una politicidad que viene a estimular la emergencia de una dramaturgia sincera y comprometida. Tal como menciona Pianca, la exigencia de esta emancipación cultural americana vendría de la mano de una nueva concepción no sólo del teatro sino de las imágenes que ese teatro debía proyectar:

Si pensamos que todas las "imágenes" son creaciones humanas (Berger), comprenderemos hasta qué punto nuestra "manera de ver" está marcada por los creadores de esas imágenes. Y cuando solamente las imágenes producidas por un cierto sector adquieren la calidad de "cultura", es obvio que nuestra "manera de ver" es el producto de la "visión de mundo" de los que le dan ese estatuto. (...) La posibilidad de crear una nueva realidad está en relación directa con la capacidad de verla. (Pianca, 1990: 26)

La precisa explicación que manifiesta la cita demuestra hasta qué punto la hipótesis planteada al inicio de este trabajo encuentra asidero en la situación bisagra entre las décadas del 60 y del 70 . La crisis del campo intelectual y teatral sobre la pertinencia de su praxis en el encuadre nacional conllevó claramente a la reflexión en el ámbito argentino -y latinoamericano- sobre la necesidad de producción de imágenes contrahegemónicas. La intuición emancipadora de una dramaturgia que viniera a dialogar con la realidad contextual demandaba, entonces, la emergencia de todo un planteo renovado sobre la constitución de la imagen, y esto sin lugar a dudas tiene que haber implicado un cambio de fondo en la aspiración formativa de nuevos autores. Es decir, el surgimiento de un deseo intelectual por constituir las imágenes de un teatro propiamente nacional que diera solución a la crisis de carencia tantas veces mencionada, no puede disociarse de los múltiples núcleos de enseñanza dramatúrgica que por entonces nacieron haciendo énfasis -paradójicamente- en el asunto de la imagen. Esto puede ilustrarse a través de cierto recorrido compacto por las propuestas didácticas de algunos de los exponentes más relevantes del campo de la dramaturgia en el contexto específico de fines de los años '60 y principios de la década siguiente.

Es inevitable, en este sentido, la referencia primera a la emblemática figura de Osvaldo Dragún. Este autor capta por esos años la necesidad pionera de focalizar no sólo 
en el tema sino también en la cuestión de la imagen, que hace de algún modo a la transmisión de cierta técnica escrituraria, la cual vertebrará su infatigable gestión de espacios de formación en dramaturgia tanto en el país como en el resto de América. La formación primeriza de Dragún pasa, como es de esperar, por cierta búsqueda individual y autónoma, ligada primero con el azar familiar y, en un momento posterior, con su trabajo iniciático en el teatro independiente:

A mí hasta los 21022 años solo me interesó el deporte (...) Pero cuando tío Juan leyó mi primera obra, hizo una lista de autores que yo debía leer: Ibsen, Chéjov, Gorki, Shaw, O’Neill. (...) De pronto reconocí un mundo que se me venía encima, que me abría todas las puertas. (En González de la Rosa y Santillán, 2014: 15-16)

Es sabido que la incorporación de este autor a la experiencia del grupo Fray Mocho resultó definitoria para su formación dramatúrgica, determinada por el contacto asiduo con la praxis de esa escena independiente. Pero lo que resulta significativo es que su incursión posterior en la enseñanza de dramaturgia no sólo impactó en el campo argentino, sino que abrió puertas impensadas a la interrelación latinoamericana con respecto a la formación de autores:

La primera vez que hice un seminario de dramaturgia, fue gracias a la inconsciencia de los cubanos. Cuando a mí me invitan a Cuba en el 61, yo acepto (...). Entonces llego a Cuba a dirigir el seminario de dramaturgia. Tenía un miedo terrible. Tenía más miedo que la gente becada para el seminario, porque no sirvo para enseñar, porque no quiero ser ejemplo de nadie. (...) Lo que sí hice fue lo que sentía, lo que necesitaba personalmente como autor. Yo necesitaba excitación para escribir. No todas las cosas importantes que pasan en el mundo son para mí excitación. (...) Pero de repente hay una noticia pequeña, que pasa inadvertida, y siento que sobre eso sí quiero escribir. (En González de la Rosa y Santillán, 2014: 57)

El Seminario de Dramaturgia que Dragún inauguró en Cuba a inicios de los años '60, no sólo constituyó una experiencia pionera a nivel latinoamericano, sino que consolidó el campo de la enseñanza de escritura teatral y condicionó, sin dudas, experiencias posteriores como la Escuela Internacional de Teatro de América Latina y el Caribe, o como también los cursos propios que el autor fue dictando esporádicamente en el ámbito nacional. El seminario cubano constaba de un taller práctico donde los textos se compartían bajo la coordinación de Dragún, y también contaba con una serie de módulos complementarios sobre literatura y teatro impartidos por figuras como Roberto Fernández Retamar o Alejo Carpentier. Lo más interesante del proyecto de Dragún radicaba en la discusión grupal de las obras en proceso de escritura y en el análisis conjunto de puestas en escena. Según el testimonio de Gerardo Fulleda, "la metodología de él era darnos un hecho, un suceso lo suficientemente poderoso como para que cada uno de nosotros pudiera hacer una obra. (...) Él nos daba un estímulo que despertara en nosotros grandes imágenes" (en González de la Rosa y Santillán, 2014: 57). Así, podemos arriesgar la idea de que este énfasis en la imagen, muchas veces estimulado por referencias al contexto socio-político inmediato, no sólo concuerda con la hipótesis macro de Piana, sino que además debe haberse sostenido en el perfil docente de Dragún durante su activa itinerancia de los años posteriores.

Por su parte, Ricardo Halac es otro de los casos que revela la importancia del período final de los años ' 60 en la emergencia de talleres pioneros de escritura teatral ${ }^{3}$. Tal como explica en un artículo al respecto:

3. Vale recordar que el estreno de Soledad para cuatro data de 1961, lo cual sitúa a este autor dentro de lo que Ordaz llamó nuevo realismo o, en términos de Pellettieri, "realismo reflexivo o crítico" (en Ordaz, 2005: 138). A partir de la representación de angustia de un núcleo social, la dramaturgia de 
En Buenos Aires, yo empecé a enseñar a escribir teatro en 1970, con Manuel ledvabni, en Teatro del Centro. Él asistía al curso con su mirada de director y al final del mismo montó un trabajo conjunto de los alumnos con actores de su grupo. Se llamaba Nadar sin respirar y se estrenó en esa misma sala. Desde el principio sentí la necesidad de que en los cursos de dramaturgia los alumnos pudieran ver qué sucedía cuando un director y varios actores corporizaban lo que habían escrito. Esa obsesión nunca me abandonó. (Halac, 2017: 51)

Más allá de esta intención pedagógica por contrastar con el resultado performático, Halac constituye ya, desde entonces, espacios de taller regidos por la metodología de la lectura en voz alta durante la clase, seguida por comentarios suyos y del resto de los asistentes. "Si miramos bien, el maestro que dicta un seminario está abocado a dos tareas: que los alumnos aprendan la técnica escribiendo, y... a que cada uno se abra y muestre su mundo propio" (52). Ese mundo propio evoca, una vez más, la necesidad de proyección genuina de imágenes personales, las cuales -al decir del dramaturgo-irían guiándose por una serie de conceptos rectores de la escritura teatral (enfrentamiento, táctica, configuración de la obra, etc.).

El Seminario para Autores brindado por Pablo Palant en Argentores resulta ser otro hito que cabe destacar en la confluencia dada hacia 1970 entre el espacio en crisis del teatro nacional y la emergente formación en dramaturgia. Si bien el seminario se había constituido dentro de la institución hacia 1958, su dilatada existencia lo ubica en un lugar central de la década siguiente (aunque estuvo marcado por cierta lateralidad e incluso llegó a tener suspensiones temporales). De todos modos, Palant logró consolidar un módulo que alcanzó a tener tres niveles y a contar con docentes colaboradores como el propio Luis Ordaz, a cargo de la materia de Teatro Argentino. Tal como ha señalado Ezequiel Lozano (2019), varias de las ideas que Palant debió haber proyectado desde su función docente en Argentores pueden recuperarse de su ensayo El texto dramático, publicado justamente hacia 1968. Allí aparece, una vez más, como si fuera un condicionamiento indeclinable del momento, la vinculación deseable entre el texto y su sociedad circundante: "Un texto es un cuerpo vivo, con alma; una disposición de elementos dirigidos a provocar un resultado, a expresar algode-alguien (el autor) que se dirige rectamente a la comunidad, de la cual es confidente y depositario" (Palant, 1968: 13). No abundan en Palant las menciones al tratamiento de la imagen. Sin embargo, algo asoma en sus análisis de textos canónicos que lo acerca en cierto modo a los planteamientos de otros colegas. En torno a Julio César, por ejemplo, desliga al autor de la importancia del modelo real, y dice al respecto:

El hombre tiene que despojarse de la soberbia de creer que el objeto no existe si él no lo ve, y tiene que decidirse, de una vez por todas, a aceptar humildemente la imaginación de los demás. Porque ese objeto que no ve y la imaginación de los demás le procurarán los elementos que necesita para terminar de reconocerse uno e indispensable, como debiera ser, y no uno y aislado, como generalmente se ve. (24-25)

La imaginación (entendida no sólo como facultad de imaginar sino como imagen en sí misma), acerca los postulados de Palant a la doble vertiente que surca el período de fines de los '60: por un lado, la deseable reciprocidad entre autor y comunidad; por otro, la aparición de la imagen como responsabilidad basal de la dramaturgia (obviamente a ser transmitida como elemento fundante de la técnica escrituraria).

Dragún, Halac, Palant: pareciera que lentamente la construcción de espacios pedagógicos para la dramaturgia va consolidando -hacia la segunda mitad de los '60- una

Halac venía a nutrir "los intentos para captar aspectos de la realidad circundante con toda crudeza, y asomar al callejón, que suponían sin salida, en el que se debatían los personajes" (138). 
estrecha relación entre la conciencia de crisis del autor nacional y la responsabilidad paulatina del surgimiento de espacios de formación dramatúrgica. Así, los talleres pioneros que emergen a principios de los años '70 irradian preocupaciones que excederán con mucho los límites del lustro siguiente. De hecho, política, imagen y enseñanza dramatúrgica vuelven a cruzarse en una anécdota postrera de la década del '70, la cual narra el propio Ordaz en su "Carta a un joven autor dramático nuestro", de 1986. Ordaz rememora allí que en los años precedentes los autores no sólo carecían de incentivos y de oportunidades sino que, además, era palpable la intención de desalentar la escritura con censura y amenazas. Y recuerda:
Allá por 1979 me encontraba al frente de un taller autoral y alguien empezó a escribir una obra en la que una madre desesperada, iba de un lado a otro buscando noticias, sin hallarlas, sobre su hijo desaparecido. Te repito el año, 1979, porque después ha sido cada vez más fácil hablar del calvario de las Madres de Plaza de Mayo. (...) Yo estimulaba para que el autor siguiera desarrollando su pieza, hasta que una tarde me confesó que había decidido abandonar la idea. Puntualizó: "Si sigo escribiendo me van a llevar preso". (Ordaz, 2005: 314-315)

Una vez más, sin embargo, la figura de Ricardo Monti viene a significar, para ese declive final de la década del '70, una especie de fuga por donde ciertas claves de salvataje no sólo logran trascender sino fundar escuela. Porque ese mismo año de 1979 donde Ordaz ve marchitarse en su taller la imagen significativa de una dramaturgia potencialmente emancipada, Monti escribe su artículo señero sobre "Las imágenes en la creación literaria". Con este texto no sólo se restituye la importancia de la imagen en el proceso creador de la dramaturgia, sino que organiza los patrones básicos que decantarían, luego, en su docencia y en la de muchos de sus discípulos. El principio fundamental será entonces no urgirse por el asedio del contexto y la responsabilidad del autor nacional partiendo -o haciendo partir al alumno- del tema reivindicativo de ciertas ideas apriorísticas. Muy por el contrario, Monti celebrará a fines de los años '70 la potencialidad política y didáctica del azar, consolidando a la imagen como punto de partida de un relato cuyo ordenamiento y sentido dependerán del devenir de la escritura. Tal como lo explica en su texto pionero, asociando el asunto de la imagen con la necesidad de la formación técnica: "El artista es un individuo que ha ejercitado, o ejercita, una especie de alerta interno que le permite detectar, fijar, desmenuzar, interrogar, orientar esa serie de imágenes, que a veces fluyen y a veces destellan espasmódicamente" (Monti, 1979: 45).

Esas imágenes, según Monti, "van iluminando por sectores, ante la mirada absorta, un paisaje que no sabemos si se va constituyendo o preexistía (...): el paisaje de la obra futura" (45). Y es a partir de esta idea que se inicia entonces un nuevo modo de pensar no sólo la dramaturgia en relación con su comunidad, sino en cuanto objeto a ser transmitido como saber. Lejos ya de las dramaturgias duras, concebidas a partir de una idea previa, y desasida también de la exigencia "comprometida" del tema, la propuesta montiana inaugura un nuevo valor de la imagen en el proceso creador. Su valor didáctico abrirá puertas al futuro, y si bien no evitará renovadas voces de alarma con respecto a la crisis del autor nacional, sí podrá contrarrestar los alertas con la proliferación de discípulos y obras que nutrirán los años subsiguientes. Monti es, de alguna manera, el eslabón último que nos permite concluir este panorama sobre la emergente formación en dramaturgia durante la transición entre los años ' 60 y los '70: una encrucijada donde la crisis de la dramaturgia nacional parece haber estimulado, efectivamente, la multiplicación de usinas para su propio futuro. 


\section{Bibliografía}

» Gonzalez de la Rosa, A., Santillán, J. J. (2014). Osvaldo Dragún. La huella inquieta. Testimonios, cartas, obras inéditas. Buenos Aires: Inteatro (INT).

» Halac, R. (2017). “'Sirve para escribir, “escribir” teatro?”, Florencio. El comentarista de Argentores, 49 (octubre-noviembre-diciembre de 2017), 50-54.

»Lozano, E. (2019). "Pablo Palant: las constantes del texto dramático y el seminario de autores noveles de Argentores", en J. Dubatti (Coordinador), XXV Jornadas Nacionales de Teatro Comparado. Ponencia inédita leída en las jornadas. Universidad de Buenos Aires, Facultad de Filosofía y Letras, Instituto de Artes del Espectáculo (IAE) / AICA - Centro Cultural de la Cooperación. Ciudad de Buenos Aires, Argentina (26 al 30 de noviembre de 2019).

» Monti, R. (1979). “Las imágenes en la creación literaria”, Memoración de Sigmund Freud, Buenos Aires: Trieb, 43-47.

» Ordaz, L. (2005). Personalidades, personajes y temas del teatro argentino, tomo 2, Buenos Aires: Inteatro (INT).

»Palant, P. (1968). El texto dramático. Buenos Aires: Centro Editor de América Latina.

》Pellettieri, O. (1997). Una historia interrumpida. Teatro Argentino Moderno (19491976). Buenos Aires: Ed. Galerna.

»Pianca, M. (1990). El teatro de Nuestra América: un proyecto continental. 19591989, Minnesota: Institute for the Study of Ideologies and Literature.

»Rozenmacher, G. (2013). "Hablaron de teatro: Cossa, Rozenmacher y Walsh. Reportaje de Pirí Lugones en cuatro escenas", en Obras completas, Col. Jorge Álvarez, Buenos Aires: Biblioteca Nacional, 879-887.

» Rozenmacher, G. (2013). “Teatro argentino. Nacionalizar a toda costa”, en Obras completas, Col. Jorge Álvarez, Buenos Aires: Biblioteca Nacional, 815-831.

\section{Entrevista}

》 Kartun, M. (2019, 31 de enero). Entrevista pública por Mariano Saba, en Buenos Aires. 